\title{
Myelin-derived and putative molecular mimic peptides share structural properties in aqueous and membrane-like environments
}

\author{
Jussi Tuusa', Arne Raasakka ${ }^{1,2}$, Salla Ruskamo ${ }^{1}$ and Petri Kursula ${ }^{1,2^{*}}$ [D
}

\begin{abstract}
Background: Despite intense research, the causes of various neurological diseases remain enigmatic to date. A role for viral or bacterial infection and associated molecular mimicry has frequently been suggested in the etiology of neurological diseases, including demyelinating autoimmune disorders, such as multiple sclerosis. Pathogen mimics of myelin-derived autoimmune peptides have been described in the literature and shown to induce myelin autoimmune responses in animal models.

Methods: We carried out a structural study on myelin-derived peptides, and mimics thereof from various pathogens, in aqueous and membrane-like environments, using conventional and synchrotron radiation circular dichroism spectroscopy. A total of 13 peptides from the literature were studied, and 290 circular dichroism spectra were analysed. In addition, peptide structure predictions and vesicle aggregation assays were performed.

Results: The results indicate a high level of similarity in the biophysical and folding properties of the peptides from either myelin proteins or proteins from pathogenic viruses or bacteria; essentially all of the studied peptides folded in the presence of lipid vesicles or under other membrane-mimicking conditions, which is a sign of membrane interaction. Many of the peptides presented remarkable similarities in their conformation in different environments.

Conclusions: As most of the studied epitope segments in myelin proteins are associated with membrane-binding sites, our results support a view of molecular mimicry, involving lipid membrane interaction propensity and similar conformational properties, possibly playing a role in demyelinating disease. The results suggest mechanisms related to protein amphiphilicity and order-disorder transitions in the recognition of peptide epitopes in autoimmune demyelination.
\end{abstract}

Keywords: Myelin, Peptide, Folding, Lipid membrane, CD spectroscopy, Synchrotron, Molecular mimicry, Structure

\section{Background}

Myelin is a multilayered, tightly packed proteolipid membrane structure crucial for the rapid saltatory conduction of nerve impulses in vertebrates. It is formed when the plasma membrane of a myelinating glial cell wraps around an axon, with eventual compaction driving out excess cytoplasm and extracellular fluid. Demyelinating diseases are neurological conditions related to the

\footnotetext{
* Correspondence: petri.kursula@uib.no

${ }^{1}$ Faculty of Biochemistry and Molecular Medicine \& Biocenter Oulu, University of Oulu, Oulu, Finland

${ }^{2}$ Department of Biomedicine, University of Bergen, Bergen, Norway
}

loss of the myelin sheath around axons. Such diseases can be caused by inherited mutations, often concerning myelin-specific proteins, or autoimmune reactions against myelin components. For most demyelinating diseases, the corresponding molecular mechanisms remain unknown, directly impairing our understanding of these disorders and their potential treatment.

Multiple sclerosis (MS) is a central nervous system (CNS) demyelinating autoimmune disease with a complex, incompletely known etiology. The current understanding of the pathogenesis and immunological models of MS has been reviewed $[1,2]$. MS is an autoimmune 
disease with an initial autoreactive, $\mathrm{T}$ cell-mediated mechanism, while B cell-expressed autoantibodies likely play a role in disease progression. Several peptide epitopes from myelin proteins, including myelin basic protein (MBP) [3], proteolipid protein (PLP) [4, 5], myelinoligodendrocyte glycoprotein (MOG) [6], and myelinassociated oligodendrocytic basic protein (MOBP) $[7,8]$ have been implicated as T cell epitopes in MS, and many such peptides have been used to induce experimental autoimmune encephalomyelitis (EAE), the most widely used animal model of MS [9]. In addition, the myelin proteins P0, P2, and PMP22 have similarly been implicated in the peripheral nervous system (PNS) autoimmune disease Guillain-Barré syndrome (GBS) and its corresponding animal model, experimental autoimmune neuritis (EAN) [10-12]. In GBS, a common diseasepreceding infection is by Campylobacter jejuni $[13,14]$.

It is unclear, how autoreactive $\mathrm{T}$ cells are triggered, but environmental factors play a significant role in MS. Especially inflammations caused by viral or microbial infections have been implicated. For example, Epstein-Barr virus infection seems to correlate with MS morbidity [2]. A number of other viral pathogens have also been implicated in MS etiology [15-18]. The proposed immunological mechanisms behind infection-induced autoimmunity include molecular mimicry, bystander activation, and dual-specificity T cell receptor (TCR) expression. While in the latter two mechanisms, the response towards the infective agent either indirectly or co-operatively induces autoreactive $\mathrm{T}$ cell function, molecular mimicry predicts immunological identity or close similarity between the sequences and/or structures of self-epitopes and viral/bacterial proteins at the molecular level.

Several viral and bacterial peptides harbour structural epitopes that mimic the well-characterized immunodominant MBP85-99 peptide, albeit they share very limited sequence similarity, with only a few conserved amino acids required for major histocompatibility complex (MHC) or TCR binding [19]. However, it is not known whether the self-epitopes are present in the native physiological state, or whether they form after conformational changes or denaturation caused by insults against myelinating glial cells and subsequent antigen presentation. MBP isolated from nerve tissue has been for long known for its intrinsically disordered structure and conformational changes induced by lipids [20-27]; much of this work stems from isolation of native protein from tissue, which will inevitably produce heterogeneous samples. Full-length 18.5-kDa murine MBP and the MBP72107 peptide underwent a disordered-to-ordered transition, when transferred from an aqueous to a membranelike environment in a trifluoroethanol (TFE) titration experiment $[28,29]$. We observed folding of recombinant
$18.5-\mathrm{kDa} \mathrm{MBP}$ in various membrane-mimetic conditions, as well as in the presence of lipid vesicles [30]. Similarly, the MBP85-99 peptide acquired helical conformation in the presence of detergent micelles and lipid vesicles [31]. The main immunogenic epitope of MBP, represented by the MBP85-99 peptide, corresponds to the central membrane attachment site, and correlations between the strength of the membrane interaction and MS etiology have been suggested [32]. Taken into account recent theories on the formation of a protein phase consisting of MBP upon myelin membrane maturation [33], it is clear that membrane binding and related conformational changes in MBP are crucial for normal myelin formation and maintenance.

The above findings raise questions on whether molecular mimicry in the context of MS may focus on structural epitopes, which change during water-lipid environmental transitions. Importantly, conformationspecific anti-MOG antibodies are required for MS-type pathological changes in EAE [34]. Therefore, there exists significant interest to find out, whether the autoimmunogenic epitopes in myelin proteins undergo conformational changes, when shifted between aqueous and hydrophobic, membrane-like environments, and whether the pathogen epitopes, which share similar $\mathrm{T}$ cell recognition, behave similarly. Could similar behaviour of peptide epitopes from myelin proteins and putative pathogenic mimics in membrane-mimicking conditions be correlated to autoimmunogenic properties in the specific case of demyelinating autoimmune diseases?

Here, circular dichroism (CD) spectroscopy was used to follow conformational changes in several myelin selfepitope peptides from PLP, MOBP, MOG, and P2 and in four MBP85-99-mimicking viral/bacterial peptides in aqueous and membrane-like environments. All peptides were picked from relevant literature. We observed that the autoimmunogenic candidate peptides underwent folding, when shifted from an aqueous to a hydrophobic environment. The same change was evident for the MBP-mimicking peptides. All the results point towards shared biophysical and structural properties in the different peptide epitopes.

\section{Methods \\ Peptides}

Synthetic peptides were from GenScript, Piscataway, NJ, USA. Details of the peptides are given in Table 1. Peptides were dissolved in sterile water to get $10 \mathrm{mg} / \mathrm{ml}$ stock solutions. All peptides were acetylated at the $\mathrm{N}$ terminus and amidated at the $\mathrm{C}$ terminus.

\section{Detergents and lipids}

$n$-Dodecyl phosphocholine (DPC) was from Anatrace and sodium dodecyl sulfate (SDS) from Sigma. Dimyristoyl 
Table 1 The peptides selected for the current study

\begin{tabular}{|c|c|c|c|}
\hline Peptide & Sequence & Predicted structure & References \\
\hline MOBP15-36 & QKFSEHFSIHCCPPFTFLNSKR & beta/disordered & [7] \\
\hline MOBP37-60 & EIVDRKYSICKSGCFYQKKEEDWI & alpha/disordered & [8] \\
\hline hMOG35-55 & MEVGWYRPPFSRWHLYRNGK & beta/disordered & [6] \\
\hline mMOG35-55 & MEVGWYRSPFSRWHLYRNGK & beta/disordered & [6] \\
\hline HSV-mimic & FRQLVHFVRDFAQLL & alpha & [19] \\
\hline EB-mimic & TGGVYHFVKKHVHES & alpha & [19] \\
\hline IA-mimic & YRNLWWFIKKNTRYP & beta/disordered & [19] \\
\hline PA-mimic & DRLLMLFAKDWSRN & alpha & [19] \\
\hline P2gbs & ENFDDYMKALGV & alpha/disordered & [78] \\
\hline PLP139-151 & VSLGKWLGHPDKF & alpha/disordered & [4] \\
\hline PLPextra2 & FNTWTTCQSIAFPSKTSASIGSLCADARMYG & alpha/disordered & {$[5,60]$} \\
\hline PLPintra1 & AEGFYTTGAVEQIFGDYKTTICGKGLSATVTGGQKGRG & mixed & {$[60,100]$} \\
\hline PLPintra2 & SRGQHQAHSLERVCHCLGKWLGHPDKFVGI & alpha/disordered & {$[4,60]$} \\
\hline
\end{tabular}

The predicted structure corresponds to that obtained from PEP-FOLD. References for the possible disease linkage of each peptide are also given

phosphatidylcholine (DMPC) and dimyristoyl phosphatidylglycerol (DMPG) were from Affymetrix. To prepare lipid vesicles, the lipids were dissolved in 1:1 methanol:chloroform. The lipid solutions were then mixed in a 1:1 molar ratio, and solvent was evaporated under a gentle air stream. The dried lipid mixtures were suspended to 10 or $20 \mathrm{mg} / \mathrm{ml}$ in water or $10 \mathrm{mM}$ HEPES (pH 7.5). Hydration was completed and unilamellar vesicles prepared by sequential sonication (30 min Branson 3510 bath sonicator, followed by $60 \mathrm{~s}$ Branson 450 ultrasonifier with $10 \%$ power and a $1 \mathrm{~s}$ pulse- $1 \mathrm{~s}$ chase protocol).

\section{Circular dichroism spectroscopy}

Environment-induced folding of peptides was analyzed by CD spectroscopy, using a Chirascan Plus spectropolarimeter (Applied Photophysics). Quartz cuvettes with a 1-mm light path were used to measure CD spectra from 260 to $190 \mathrm{~nm}$. The samples were water-dissolved peptide samples of nominal concentrations of 50 to $100 \mu \mathrm{g} / \mathrm{ml}$, with or without TFE, detergents, or lipids (added immediately before the measurement). A peptide form the Plasmodium falciparum formin was used as a negative control. Synchrotron radiation CD (SRCD) spectra were recorded at $+30{ }^{\circ} \mathrm{C}$ on the DISCO beamline at the SOLEIL synchrotron (Paris, France) and on the AU-CD beamline at the ASTRID2 storage ring (ISA, Aarhus, Denmark), using 0.2and $0.5-\mathrm{mm}$ quartz cuvettes and $0.25 \mathrm{mg} / \mathrm{ml}$ peptide.

In the oriented $\mathrm{CD}(\mathrm{OCD})$ experiment, $200 \mu \mathrm{l}$ of a peptide-lipid (1:30 molar ratio) mixture, containing $10 \mu \mathrm{g}$ of peptide, or $200 \mu \mathrm{l}$ of a DMPC:DMPG (1:1) lipid blank alone, were pipetted onto a quartz disk. The generation of multilamellar planar lipid bilayers was conducted by air-drying, followed by $10 \mathrm{~h}$ of re-hydration in a saturated $\mathrm{K}_{2} \mathrm{SO}_{4}$ atmosphere at $+30{ }^{\circ} \mathrm{C}$ (relative humidity 97\%) [31]. OCD spectra were recorded with $45^{\circ}$ rotation steps on the DISCO beamline at the SOLEIL synchrotron (Paris, France), and the resulting eight spectra, covering $360^{\circ}$ of total rotation, were averaged. Due to the rather harsh sample preparation procedure and the tendency of the peptides to aggregate membranes, only the EB-mimic peptide gave a high enough signal for further analysis.

SRCD and OCD spectra were averaged and backgrounds subtracted with CDtool [35]. A total of $290 \mathrm{CD}$ spectra were measured and analysed.

\section{Structure prediction and $\mathrm{CD}$ deconvolution}

De novo structure prediction of the peptides was done in silico using the PEP-FOLD server [36, 37]. Membrane association modes of protein and peptide models where predicted using PPM [38]. Secondary structure contents were inferred by deconvoluting the $\mathrm{CD}$ spectra with the DICHROWEB server using the CONTINLL algorithm with DICHROWEB reference databases 6 and 7 for SRCD and regular CD, respectively [39]. The Bestsel server [40] was also used. It should be noted that in the case of short peptides, deconvolution algorithms optimized for full proteins give semi-quantitative or qualitative results, and we think more information is available by simply observing and comparing the full spectra, instead of relying on numbers from deconvolution. Spectra of short peptides are strongly affected by amino acid composition, for example.

\section{Turbidimetry}

Peptide-induced vesicle agglutination was studied in $0.5 \mathrm{mM}$ DMPC:DMPG lipid in water. Peptides or proteins were added at the start of the experiment, and the 
experiment was carried out essentially as described before [41]. The full-length human P2 protein was used as a positive control [41]. Another possible positive control could have been full-length MBP [42].

Turbidity changes as a function of peptide concentration were followed by absorbance measurement at $450 \mathrm{~nm}$ in 96-well format using a Tecan Infinite M1000 Pro plate reader (Tecan, Salzburg, Austria). The total volume was $150 \mu \mathrm{l}$, and $2 \mathrm{~s}$ orbital shaking with $1 \mathrm{~mm}$ amplitude and $150 \mathrm{~ms}$ settling time were used.

\section{Results}

Demyelinating autoimmune diseases, such as MS or GBS, are thought to present a molecular mimicry component related to relatively common viral or bacterial pathogens, many of which involve the nervous system in their infection. This research was sparked by our interest in studying putative common biophysical properties between myelin-derived autoimmune peptides and peptides from pathogens described in the literature and proposed to cause molecular mimicry in e.g. multiple sclerosis. Our hypothesis was that such peptides might share similar properties with respect to structure, conformational changes, and lipid membrane binding, and furthermore, that peptides affecting the CNS and PNS might have similar properties.

\section{Myelin-derived or myelin-mimicking peptides of potential relevance to demyelinating disease}

Nine peptides from four human or mouse compact myelin proteins with a putative autoimmunogenic character and four viral/bacterial peptides suggested [19] to mimic the well-known MS-associated MBP sequence (amino acids 85-99) were chosen for structural analysis; all peptides have been described in the literature earlier (see Table 1 and references therein). The corresponding MBP85-99 peptide was a subject of our earlier study [31]. An additional common denominator of the myelin protein peptides was known or suggested membrane contact. The $\mathrm{N}$ terminus of MOBP is predicted to have a membrane-associated FYVE domain [43]. The peripheral myelin protein P2 acts in the formation of myelin membrane stacks, with the two $\alpha$ helices involved in membrane contacts $[41,44]$. MOG and PLP are transmembrane proteins, in which both the extracellular and cytoplasmic domains may interact with the next apposing lipid bilayer. In PLP, the autoimmunogenic peptides are in the close vicinity of the transmembrane domains, forming loops between them. Finally, pathogen-derived peptides were predicted to mimic the autoimmunogenic central membrane-anchoring segment of MBP, which has been shown to become embedded into the lipid bilayer [19, 31, 45-49].
Based on amino acid sequences, the peptides do not exclusively share obvious biophysical characteristics. However, most of the peptides are positively charged at neutral $\mathrm{pH}$ and contain hydrophobic amino acids, which may be important for membrane attachment (Additional file 1: Table S1). The charge distributions are evenly scattered along the sequence. However, most peptides showed amphipathic distribution of positively charged and hydrophobic residues on helical wheel models (Fig. 6b, Additional file 2: Figure S1), possibly reflecting propensity for interactions with phospholipid membrane surfaces. A predicted property for most, but not all, of the studied peptides is the presence of a membraneinduced amphipathic helix.

The peptide de novo structure was predicted in silico using the PEP-FOLD algorithm [36] (Additional file 3: Figure S2). The MOG-derived peptides, as well as the Influenza hemagglutinin peptide (IA mimic), were predicted to harbor $\beta$ strands, whereas other MBPmimicking peptides (HSV mimic, EB mimic, and PA mimic) as well as the P2-derived peptide P2gbs, contained an $\alpha$ helix as the dominant predicted secondary structure. The latter corresponds to $\alpha$ helix 1 in the crystal structure of human P2 [41, 44]. Peptides from PLP were predicted to consist of $\alpha$-helical parts with a $\beta$ strand (PLPintra1) or disordered sequences (Table 1), while MOBP15-36 and MOBP37-60 were predicted to have $\beta$ strand and $\alpha$ helix, respectively, in addition to disordered regions (Table 1). While all peptides were experimentally observed to maintain an unfolded structure in aqueous solution, these predicted propensities of folding were, in fact, rather consistent with CD spectroscopic experiments under membrane-mimicking conditions (see results below).

During the formation of compact myelin, the peripheral membrane proteins of myelin, as well as the extraand intracellular domains of integral myelin membrane proteins, experience change from an aqueous/single membrane physical environment to a dehydrated membrane multilayer. After mechanical damage, or an inflammation/infection-induced insult to myelin, an opposite environmental change is possible, whereby membrane-embedded epitopes may be exposed to aqueous conditions. CD spectroscopy is a powerful method to probe solvent effects on peptide structure. Previously, it has been shown that many myelin protein-derived peptides, indeed, undergo folding, when shifted from aqueous buffer into a more hydrophobic environment $[31,50]$. We monitored the CD spectra of the 13 selected peptides (Table 1) by conventional and SRCD in the presence of different concentrations of TFE, DPC, and SDS, as well as with DMPC:DMPG (1:1) vesicles.

In general, all studied peptides were disordered in water and showed TFE-, SDS- (a negatively charged 
detergent, critical micellar concentration $\mathrm{CMC}=8.2 \mathrm{mM}$; $\sim 0.24 \%$ ), and lipid vesicle-induced folding at variable levels, while DPC (a zwitterionic detergent, $\mathrm{CMC}=$ 1.1. $\mathrm{mM} ; 0.04 \%$ ) did not induce folding of MOBP peptides (see below for details). Of note, a peptide from the formin of the malaria parasite did not fold upon membrane-mimicking conditions and was considered a negative control (Additional file 4: Figure S3). Consistently, CONTINLL predicted higher degrees of folding and higher $\alpha / \beta$ ratios than the Bestsel algorithm. However, these differences were minor in terms of quantity. Finally, as expected, the diagnostic value of the wavelength region 180-190 $\mathrm{nm}$, which can be reliably measured only with SRCD, was significant. This could be observed by comparing the secondary structure content deconvolutions between conventional CD (190-260 nm) and SRCD (180-270 nm), as the programs inferred conventional $\mathrm{CD}$ spectra in favour of $\beta$ strand content, which likely arose from random coil structure, as indicated by SRCD data. The results from secondary structure deconvolution of all 290 CD spectra with both of the algorithms are given in Additional file 5: Table S2.

\section{MBP85-99-mimicking peptides demonstrate a major disorder-to-helix transition induced by TFE, micelles, and lipid vesicles}

The four MBP85-99-mimicking peptides (Fig. 1a), 'HSVmimic' from tripartite terminase subunit 3 (UL15) of Human herpes simplex virus 1, 'EB-mimic' from EpsteinBarr virus DNA polymerase catalytic subunit (BALF5), 'IA-mimic' from Influenza $A$ virus hemagglutinin, and 'PA-mimic' from Pseudomonas aeruginosa phosphomannomutase $(\mathrm{algC})$, were selected based on earlier literature on their properties related to molecular mimicry in autoimmune response [19]. Structural information for the corresponding segment in MBP is available (Fig. 1b, c), and while it is helical when bound to membranes [31, 47], its conformation is extended when bound to MHC [51]. The residues most conserved between MBP and the mimic peptides lie slightly embedded in the membrane in

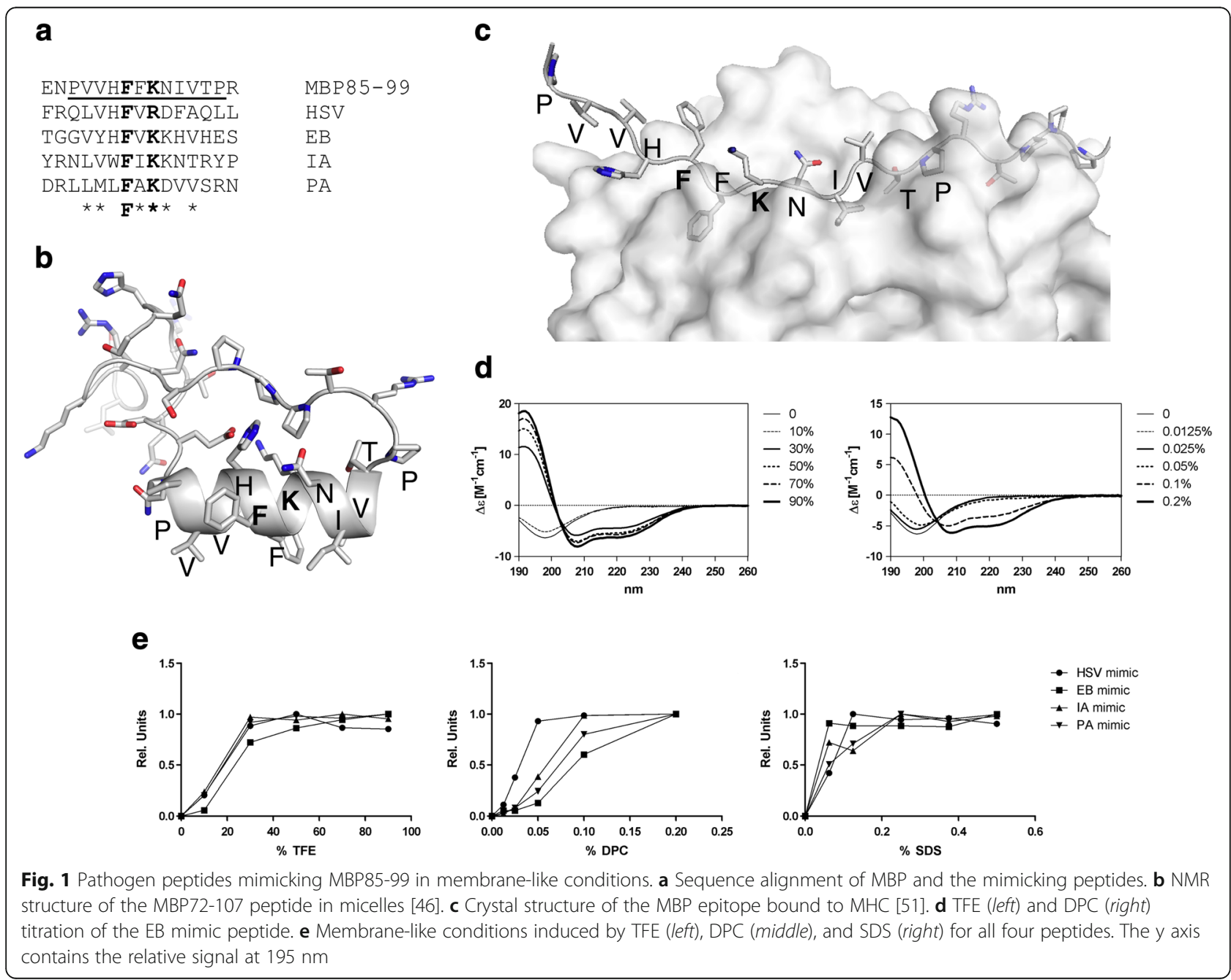


the helical conformation, and they point outward from the MHC complex; these are the positions that MHC presents to the T cell. Mutation of these positions in the MBP85-99 epitope lead to altered immunological response [52, 53].

In $\mathrm{CD}$ experiments, the mimic peptides were mainly disordered in water and acquired folded structure after moving into membrane-like environments (Fig. 1d, e and Additional file 5: Table S2). This behavior is highly similar to that of the MBP85-99 peptide [31]. From the SRCD spectra of peptide-lipid vesicle mixtures (Fig. 2), CONTINLL and Bestsel, respectively, calculated $\alpha-$ helical contents of 91 and $79 \%$ for EB-mimic, 57 and $58 \%$ for HSV-mimic, 63 and $62 \%$ for IA-mimic, and 43 and $38 \%$ for PA-mimic. Interestingly, while the predicted structure de novo (Table 1) was helical for EB-mimic, HSV-mimic, and PA-mimic, IA-mimic was predicted to have a $\beta$ strand, which is also present for this segment in the hemagglutinin protein [54]. Similarly to MOG35-55 (see below), the IA-mimic peptide thus shows, at least as an isolated peptide, that it has a propensity for helical conformation under membrane-like conditions. Such common properties may explain the encephalitogenic properties of many myelin- and pathogen-derived peptides, despite the context of the corresponding sequence in the full protein.

\section{The EB-mimic peptide membrane orientation is similar to MBP85-99}

Previously, we [31] have shown by OCD that MBP85-99 is partially embedded into a lipid membrane leaflet in a tilted orientation. We repeated the experiment here for the EB mimic peptide, which had the highest helical content when mixed with vesicles (see above). Briefly, $10 \mu \mathrm{g}$ of peptide was mixed with DMPC:DMPG (1:1) vesicles with a 1:30 $\mathrm{P} / \mathrm{L}$ ratio, and $\mathrm{OCD}$ was measured from planar multilayered membranes. The 208-nm minimum, typical for $\alpha$-helical conformation, which was observed in isotropic solution CD spectra, was missing in OCD (Fig. 3), indicating either a conformational change or assembly of the peptide in a tilted orientation in the oriented membrane layers. This observation supports the hypothesis that the MBP85-99 self-epitope and the mimic peptides share similar conformational epitopes.

\section{The MOG35-55 epitope has a propensity to adopt helical conformation}

The MOG35-55 epitope (Fig. 4a) is a widely recognized inducer of encephalitogenic reactions, and it is routinely used to induce mouse EAE models [55, 56]. The mMOG35-55 epitope is highly immunogenic and induces EAE, while the corresponding peptide from human MOG is less active in causing EAE [57]. This is surprising, since only one residue distinguishes mMOG35-55 and hMOG35-55 from each other.

Both human and mouse MOG35-55 were largely disordered in water and acquired $\alpha$-helical character in hydrophobic environments (Fig. 4). While these peptides differ only by a single amino acid (Pro/Ser42), the $\alpha / \beta$ ratio was in general higher for hMOG35-55 in membrane-mimicking conditions (Fig. 4, Additional file 5: Table S2). The SRCD spectra of the two peptides with lipid vesicles also suggest more $\beta$ structure content for mMOG35-55 (Fig. 4b). In the crystal structure, the peptide sequence covers two $\beta$ strands and a connecting loop [58] (Fig. 4a), which was also predicted for these peptides de novo in aqueous environment (Table 1). However, based on our results, this autoimmunogenic region in MOG has an intrinsic propensity to adopt $\alpha$-helical conformation in the context of a peptide interacting with membranes. Subtle differences in folding between the mMOG35-55 and hMOG35-55 epitopes may be relevant
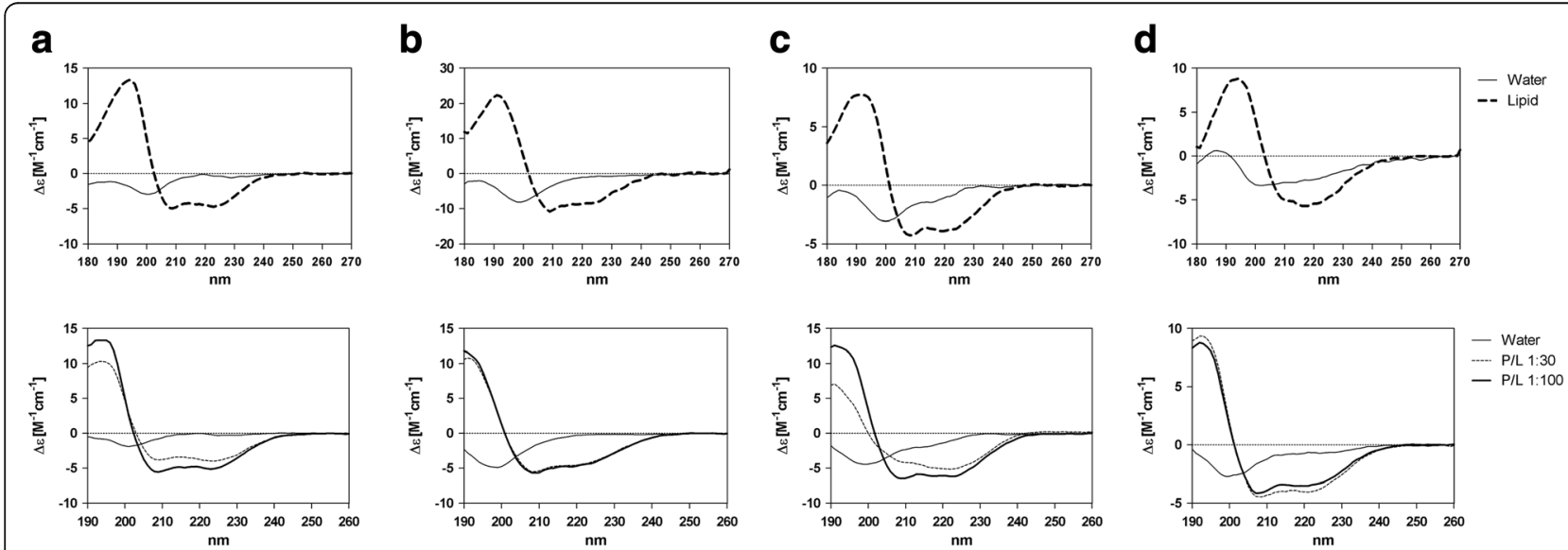

Fig. 2 MBP-mimicking peptides in lipidic environment. The top panel shows SRCD spectra in water and with lipid vesicles (dashed line), and the bottom panel conventional CD spectra at two different P/L ratios. a HSV-mimic. b EB-mimic. c IA-mimic. d PA-mimic 


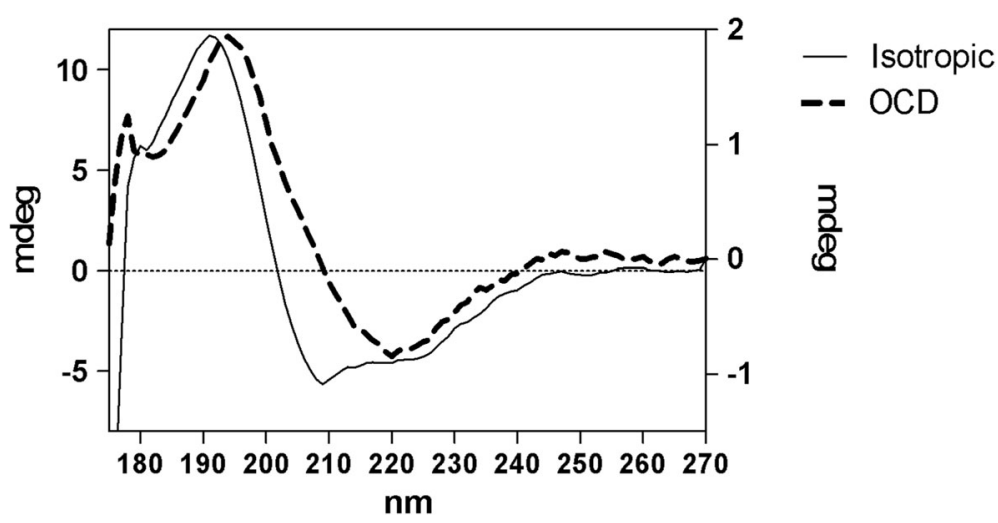

Fig. 3 Orientation of the EB-mimic peptide on a membrane. The figure shows comparison of isotropic and oriented SRCD spectra. The loss of the peak at $208 \mathrm{~nm}$ in OCD is a sign of tilting of the peptide with respect to the membrane surface plane

for inducing EAE with MOG peptides. Mutations in the mMOG35-55 peptide have also been linked to altered immune responses in mouse models [59]. Whether the recognition of the Pro/Ser residue itself or the variantfavored conformation determines the strength of autoimmunogenicity remains to be studied.
MOBP peptides fold into different structures in membranes

The $\mathrm{N}$ terminus of MOBP, shared by all known MOBP isoforms, is predicted to fold into a FYVE-like membrane interaction domain [43] (Fig. 5a, b). The epitope peptide segments correspond to areas predicted to

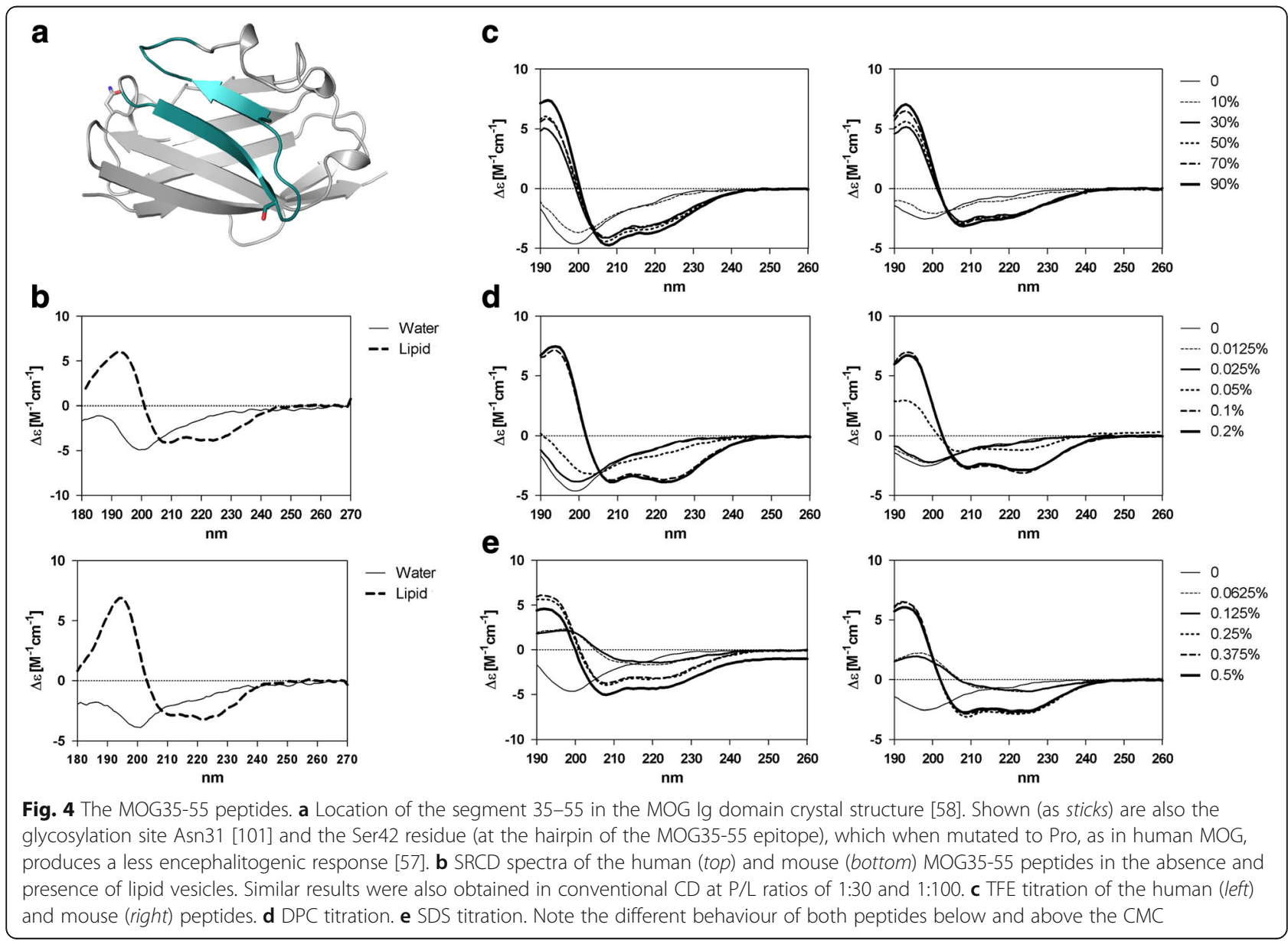




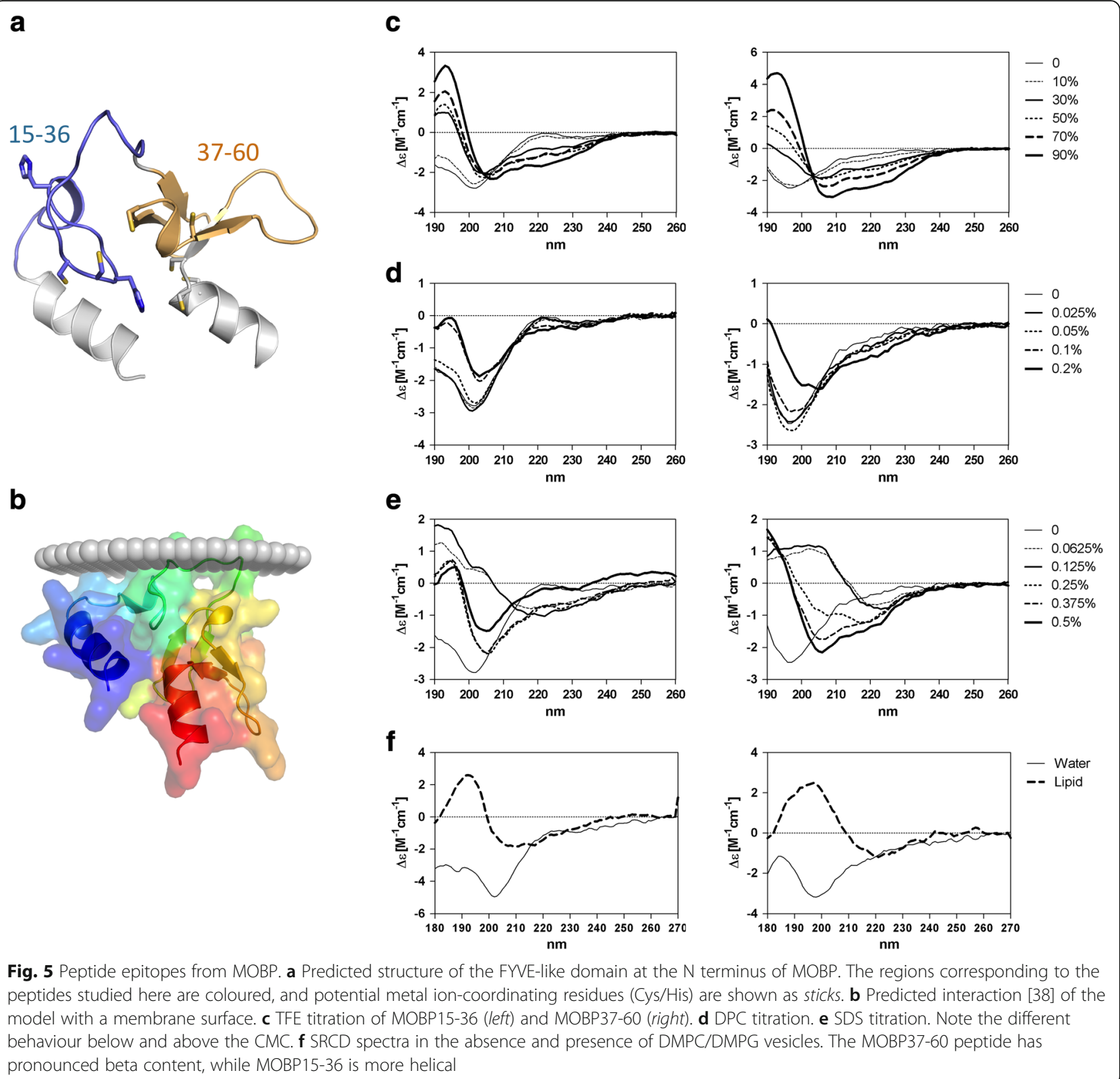

closely interact with the lipid membrane surface. So far, no high-resolution structural or functional studies with purified MOBP protein have been carried out. The de novo prediction suggested some $\beta$ and $\alpha$ structures for the MOBP15-36 and 37-60 peptides, respectively, with disordered regions (Table 1), but in contrast to the MBP-mimicking and MOG35-55 peptides, models predicted by PEP-FOLD were not always consistent.

Both MOBP peptides (15-36, 37-60) showed hydrophobicity-induced folding (Fig. 5b-f). DPC induced some secondary structure formation at high concentrations (Fig. 5d), while both peptides behaved differently in SDS. Below the CMC of SDS, the CD spectra are reminiscent of $\beta$ aggregates, while above the $\mathrm{CMC}$, micelles of SDS induce significant helical components (Fig. 5e). The SRCD spectra of lipid vesicle-induced folding suggested a $\beta$ sheet structure for MOBP37-60, while MOBP15-36 contains more helical structure (Fig. 5f). While these results differ somewhat from the other peptides in this study, which form $\alpha$-helical structures under most conditions, they are logical and fit to the predicted FYVE domain structure of MOBP [43].

\section{PLP-derived peptides fold in hydrophobic environments}

The peptides from PLP were based on earlier studies on EAE models, and included both extra- and intracellular 
epitopes (Fig. 6a) shown to induce antibody responses related to demyelination in EAE [60, 61]. In the overlapping peptides PLP139-151 and PLPintra2, a region with strong propensity to fold into an amphipathic helix can be detected (Fig. 6b, c). Remarkably, all the PLP peptides also exhibited folding in membranous environments, although they are expected to represent loops between the transmembrane helices in the PLP protein (Fig. 6d, e). The result strongly suggests that these loops are able to interact directly with lipid membrane surfaces. In the case of compact myelin, this could lead to a single molecule of PLP acting as glue between three successive membrane layers. Interestingly, a $\mathrm{C}$-terminal peptide from PLP was also recently shown to fold upon membrane interaction, and the folding was affected by peptide concentration, the helices refolding into $\beta$ sheet structure at high concentration on the lipid membrane a process, which might play a role in myelin membrane stacking [62].

The peptides PLP139-151 and PLPintra2 overlap, PLPintra2 being an extended version of the widely used encephalitogenic PLP139-151 peptide. Furthermore, the region covered by PLPintra2 corresponds nearly exactly to the segment missing in the alternatively spliced DM20 isoform of PLP. DM20 is believed to be less adhesive in membrane multilayers than PLP [63]. The fact

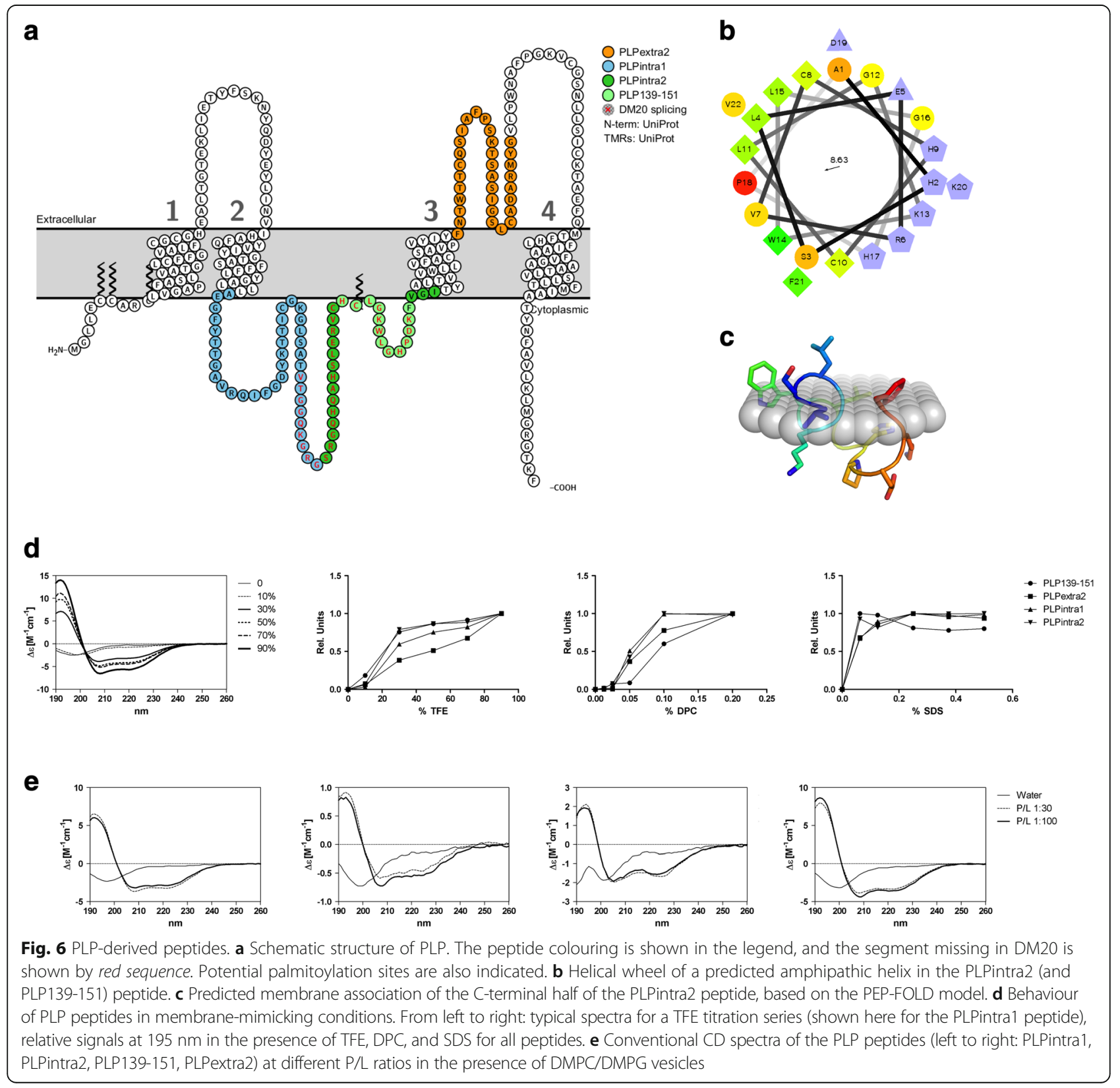


that peptides corresponding to the region missing in DM20 show clear, strong folding events in membranelike environments suggests that indeed, a membranebinding site is removed from DM20 during alternative mRNA splicing. It is likely that this segment folds into an amphipathic helix onto the membrane surface (Fig. 6c); this propensity should be further strengthened by hydrophobic post-translational modifications (palmitoylation) on the two Cys residues, as suggested by a helical wheel representation (Fig. 6b).

The palmitoylation of the Cys residues has been observed to induce greater $\mathrm{T}$ cell and antibody responses in both EAE mice and MS patients compared to nonacylated peptides $[64,65]$. This further supports the relevance of the hydrophobic surface of an amphipathic helix to the immunogenicity of PLP139-151 and PLPintra2 peptides. We believe that this segment is a strong membrane anchor in PLP. Whether it binds to the same or the apposing membrane surface in myelin, is currently unknown. Both scenarios would explain stronger adhesive properties of PLP in comparison to the DM20 isoform.

During evolution, the 35-residue segment distinguishing PLP from DM20 has been acquired in terrestrial vertebrates $[63,66]$. Simultaneously, the expression of myelin protein zero (P0) in the CNS has been lost. This points towards a scenario, where the evolution of terrestrial vertebrates at the myelin molecular level has involved the loss of P0-mediated adhesion (which still is crucial in the PNS) and the acquirement of an additional adhesive segment in the cytoplasmic domain of PLP/ DM20. PLP has a strong tendency to form dimers in transfected COS cells, primary oligodendrocytes, and in brain tissue, while DM20 exists mainly as a monomer. Cys108, located in the common part of intracellular loop of PLP/DM20, as well as in the PLPintra1 peptide, is involved in the dimerization of PLP [67].

Both the PLP139-151 and PLPintra2 peptides include a 'stop transfer signal' (residues HPDK ${ }^{150}$ ), which restricts the ability of transmembrane helix 3 to shift in the cases of mutations in the second extracellular loop of PLP. These charged residues are omitted from DM20, enabling the movement of the transmembrane domain inside the membrane [68]. Thus, in some cases, the middle part of the PLPintra1 peptide (residues GLSAT ${ }^{115}$ ) forms an extension of transmembrane helix 3 and can be embedded into the membrane. Several PLP139-151 epitope-mimicking peptides, not studied here, are also known e.g. from Acanthamoeba castellanii [69] and Haemophilus influenza [70]. Whether they share properties with PLP139-151 remains a subject for future research.

The second extracellular loop of PLP contains two disulphide bonds, located between Cys183-Cys227 and Cys200-Cys227, respectively. The membrane-proximal disulphide bond (Cys183-Cys227) is fundamental to the proper cell surface expression of PLP, and it is involved in Pelizaeus-Merzbacher disease [71]. The PLPextra2 peptide contains only two Cys residues (Cys183 and 200) and cannot form these disulphide bonds. However, all membrane-mimicking conditions induced an $\alpha$ helical folding of the PLPextra2 peptide (Fig. 6d, e and Additional file 5: Table S2). Dhaunchak and Nave [71] also reported that the cell surface expression of PLP can be rescued if the cysteines in the second extracellular loop are mutated, indicating that the disulphide bonds are not crucial for the normal folding of the second extracellular loop.

The deconvolution of spectral data suggested $30-40 \%$ helical content in membrane vesicles for PLPextra2 and PLPintra1, which is consistent with the de novo predicted situation with partially folded and disordered state (Table 1). Although the change in spectrum indicated increased $\alpha$-helical nature for PLPintra2, the calculated content of $\alpha$ helices was modest. This may be an underestimate due to putative aggregation, which is discussed below.

\section{Membrane-induced folding of the GBS epitope from human peripheral nerve protein $\mathbf{P} 2$}

P2 is one of the structurally best-characterized myelin proteins, being highly expressed in PNS myelin [72, 73]. It is a proposed target of autoimmune reactions in GBS, and $\mathrm{P} 2$ peptides can be used to induce EAN, the mouse model of human GBS $[74,75]$. P2 is able to stack lipid bilayers together in an ordered manner in vitro $[41,76,77]$, and the P2 knockout mouse has changes in myelin lipid composition and motor nerve conduction velocity during periods of active myelination [73].

The peptide studied here corresponds to the GBS epitope characterized earlier [78], and in the crystal structure, it comprises the first $\alpha$ helix of the lid of the 10stranded $\beta$-barrel structure [44] (Fig. 7a). It is likely that the helical lid is centrally involved in membrane interactions during membrane stacking [79].

The P2gbs peptide showed helical folding at DPC and SDS concentrations above the CMC, and strong helical folding was present at 30\% TFE (Fig. 7b-d). With lipid vesicles, a helical spectrum was observed in SRCD experiments, further indicating induction of $\alpha$-helical folding of P2gbs in membrane-like conditions (Fig. 7e). While these results are not unexpected in light of de novo predictions (Table 1, Additional file 3: Figure S2) and the fact that the sequence is helical in the crystal structure and predicted to contact the membrane, they provide striking similarity to the CNS antigen peptides described above. Similar molecular mechanisms and principles could, thus, be involved in demyelinationrelated autoimmunity in the CNS and PNS. 


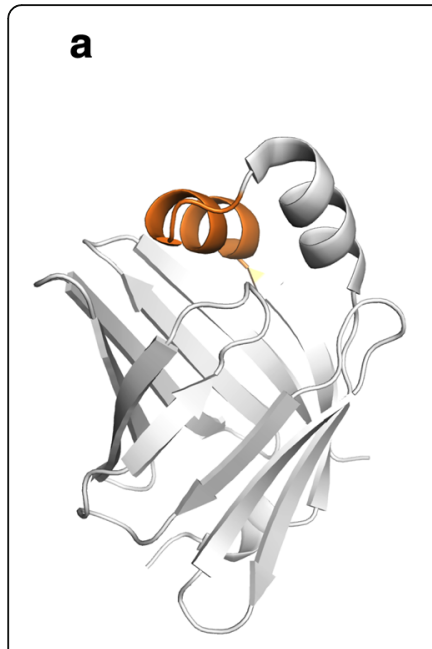

b

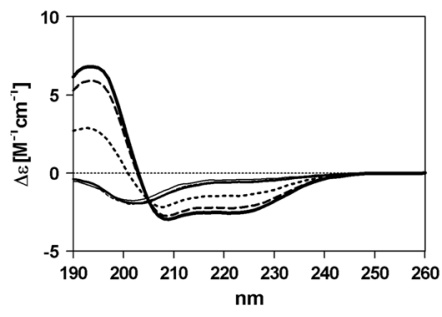

d

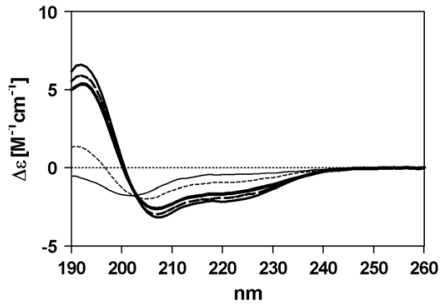

C

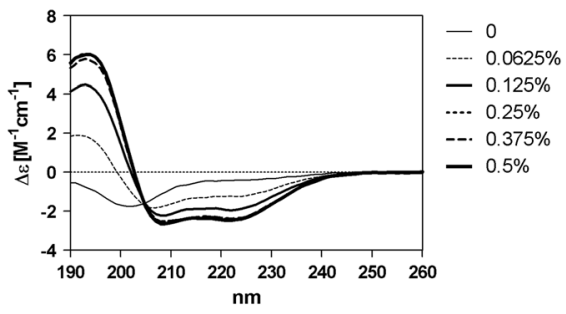

e

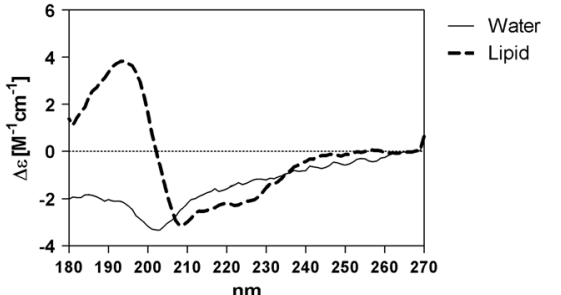

Fig. 7 The GBS epitope in P2. a The GBS epitope corresponds to the first a helix in the P2 crystal structure [44]. The two helices form a lid, proposed to interact with the myelin membrane and possibly open upon ligand entry and release [79]. b DPC titration. c SDS titration. $\mathbf{d}$ TFE titration. e SRCD spectra with and without lipid vesicles

\section{Turbidimetry shows peptide-induced vesicle agglutination}

In SRCD, one generally can use shorter pathlengths, and hence, much higher sample concentrations than in conventional $\mathrm{CD}$, which has the problem of light intensity falling off at lower wavelengths. During SRCD experiments, peptide-induced aggregation was observed when lipid vesicles were added into solutions of high $(0.5 \mathrm{mg} / \mathrm{ml})$ concentrations of peptides. This was most severe for the EB-mimic, MOG35-55, and PLPintra2 peptides (data not shown). The problem could be circumvented by using lower peptide concentration $(0.25 \mathrm{mg} / \mathrm{ml})$ with a high (1:100) peptide:lipid ratio in SRCD experiments; this observation also triggered us to investigate the agglutination potency of the studied peptides more closely.

The monitoring of lipid vesicle aggregation was done by measuring absorption (turbidity) at $450 \mathrm{~nm}$ after mixing vesicles with increasing concentrations of peptides (Fig. 8a). Although the peptide-induced aggregation was modest compared to protein P2-induced agglutination (Fig. 8b), reproducible vesicle agglutination was detected for the EB-mimic, hMOG35-55, mMOG35-55, and PLPintra2 peptides, and occasionally also for IA-mimic and PA-mimic (Fig. 8 and data not shown). The observation of turbidity could indicate a propensity of the peptide to stack membrane bilayers together into multilayers (mimicking myelin); in the least, it is a sign of altered surface properties of the lipid membrane, promoting aggregation. Hence, we consider turbidity a functional assay for myelin membrane-stacking proteins/ peptides. Having this property not only in myelin protein peptides, but also in some of the molecular mimics, further indicates common properties for the studied encephalitogenic peptides.

\section{Discussion}

Despite huge efforts in the past decades, MS has so far evaded the deciphering of its pathogenesis. We do know that in rodent EAE models, an active immunization with myelin antigens, or a passive adoptive transfer of myelin-specific autoreactive Th1/Th17 CD4 lymphocytes, phenocopies many features of MS [80-82]. There exists also understanding that the genetic susceptibility via the HLA-DR15 haplotype and certain environmental factors, such as infection by herpes viruses, especially by Epstein-Barr virus, are significant risk factors for MS [83]. However, we do not know whether induction of autoimmunity in MS takes place primarily in the periphery (like in EAE) or in the CNS. In the early stages of MS, the presence of infiltrated T lymphocytes predominates, while in later stages, CNS inflammation becomes self-sustainable, and the number of B cells in lesions increases [2]. However, we do not know the relative importance of CD4 and CD8 T cells or the exact roles of $\mathrm{B}$ cells and antibodies. Finally, although the structural similarity between the MHC II-bound MBP-derived peptides and their molecular mimics, like those from EBV polymerase, can explain how the mimic-specific TCRs in CD4 T cells can recognize self-antigens [84, 85], we lack structures of $\mathrm{MBP} / \mathrm{mimic}$-bound $\mathrm{MHC}$ I complexes. The latter are important, as cytotoxic CD8 T cells can directly attack the oligodendrocytes, which present peptides to them [86]. Neither do we know whether the 

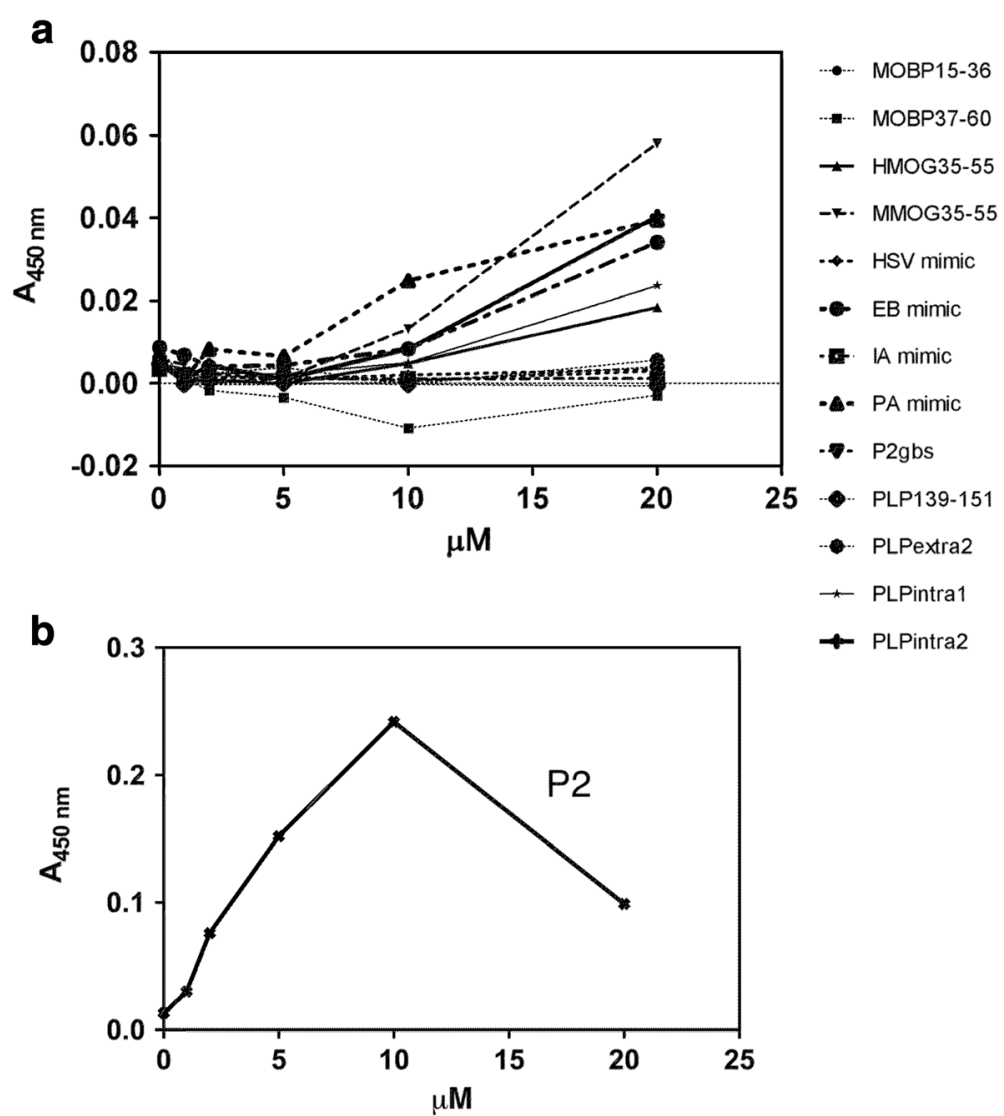

Fig. 8 Turbidimetric analysis of all studied peptides. a Turbidity of each peptide-vesicle mixture was determined after a 10-min incubation. b The human myelin protein P2 acts as a positive control for the assay. Note how concentrations above $10 \mu \mathrm{M}$ decrease turbidity; this is caused by precipitation of the vesicle aggregates

autoantibodies, which recognize folded epitopes like those in MOG, may be induced by mimicking antigens.

MBP is the best-characterized myelin protein, both at the level of the full-length protein and as peptide segments. Much of the early research was carried out using MBP purified from tissue [20-25, 27], and more recently, recombinant MBP has also been intensively studied $[29,30,48,49]$. According to the current view, MBP is intrinsically disordered in solution, but folds into short helical segments upon membrane binding [87]. The structure of MBP on membranes can be further affected by the lipid composition. Here, we did not assess the effects of different lipid compositions on peptide folding, but earlier research has shown that the helical structure of the autoimmune epitope of MBP does slightly change in different lipid membrane compositions $[45,88]$. This is of interest because demyelination is linked to changes in lipid composition, and these changes may in turn alter the conformation, localization, and properties of MBP [89]. Furthermore, the epitope conformation may be affected by its presence in either a peptide or a full-length MBP protein [46, 47]. For obtaining detailed local conformational information, we chose here to focus on short peptide segments. Even for the longest peptides, we believe that the membrane-binding segments will be short helices, as predicted de novo (Additional file 3: Figure S2).

How do our observations of the common membraneinduced folding of MBP mimics, and most other peptides studied here, fit into this big picture? It is possible that the propensity to adopt $\alpha$-helical structure in the experiment merely illustrates similar biophysical properties. However, it is also possible that these peptides do adopt a helical structure in vivo, with relevance to the generation of autoimmunity per se. Two speculative hypotheses can be presented.

Firstly, the relatively low affinity and non-standard geometry in the binding of TCRs to MHC II-peptide complexes can explain the escape of self-reactive $\mathrm{T}$ cells from negative selection [90]. In the known MHC II$\mathrm{MBP} /$ mimic structures, the peptide binds $\mathrm{MHC}$ in an extended conformation [84, 85]. Whether the peptide propensity to fold affects rescue from negative selection is not known. It can be speculated that during the 
generation of $\mathrm{T}$ cell tolerance, the amount of MHCloadable non-folded self-peptides is low, but may become significant after inflammatory insult. Interestingly, the presence of autoantigenic MBP peptides in the spectrum of proteasomal products increases after MBP immunization [86]. Secondly, it is possible that mimicspecific, such as Epstein-Barr virus-infected and CNSinfiltrated, memory B cells [91] may have affinity against myelin neoepitopes that are exposed in degenerated/ insulted myelin.

Neither scenario above suggests that membraneinduced folding universally leads to auto-immunogenicity, but it could be relevant in rare cases where both 1) the environment-induced conformational changes of myelin proteins can lead to changes in processing and/or peptide loading to affect negative selection of $\mathrm{T}$ cells or creation of neoepitopes for B cells and 2) the mimicking agent is present at the critical time. It is obvious that many hydrophobic self-sequences are strongly immunogenic [92, 93], but the corresponding $\mathrm{T}$ cells go to apoptosis in the thymus. An animal model with genetic or external exposure of myelin proteins/peptides, which do not significantly change the structure of the host protein, but alter membrane-induced conformational changes, might be useful to test these hypotheses.

\section{Conclusions}

The understanding of myelin autoimmunity at the molecular level is poor, also taking into account the fact that myelin protein epitopes in general are buried within the myelin sheath, a tightly packed multilayered membrane. On the other hand, these epitopes are hidden from the immune system in a healthy myelin environment, and might only be exposed in case of prior insult to the myelin membrane. All our experiments point towards highly similar properties for all the studied peptides. In this respect, it is of interest to note the possible potential of myelin protein-derived peptides in MS therapy; these include both cyclic and mutated variants of myelin antigen peptides, especially MBP85-99 [59, 94-98]; the design of such peptides could also take into account our observations on similar overall structural and membrane interaction properties of peptides with limited sequence similarity per se. While the link between membrane binding, membraneinduced folding, and autoimmune response is unclear, molecular mimicry possibly taking place in autoimmune demyelination may be based on 3D similarity of host and pathogen epitopes. In the case of MBP85-99 mimics, for example, while the peptides fold into amphipathic helices on lipid membranes, the extended conformation bound to the MHC shows the conserved residues being presented outwards, being important for immune response.
Our results give new insights into myelin proteinmembrane interactions within short segments of the protein; the situation in the case of full-length proteins is of course more complex. For protein-peptide interactions, both electrostatic interactions and conformational flexibility are important factors in recognition and binding [99]. In the case of flexible proteins, such as MBP, a multitude of conformations are present [29, 87], and antibody binding might reflect a fortuitous capture of specific conformations that become more rigid. The conformations of MBP peptides on the membrane surface and when bound to MHC may reflect such a phenomenon. Similar properties between different peptide epitopes may provide means to multifaceted, but shared, recognition mechanisms, which in turn may relate to disease etiology. It is clear that more research in in vivo systems will be required to gain further answers to these questions in the case of autoimmune demyelination.

\section{Additional files}

Additional file 1: Table S1. Details of peptide properties. (PDF $60 \mathrm{~kb}$ )

Additional file 2: Figure S1. Helical wheel predictions of all peptides from this study. (PDF $1382 \mathrm{~kb}$ )

Additional file 3: Figure S2. PEP-FOLD model predictions for the studied peptides. (PDF $398 \mathrm{~kb}$ )

Additional file 4: Figure S3. CD spectra for a negative control peptide from the $P$. falciparum formin display no folding under membranemimicking conditions. The peptide sequence is KKIPAPPPFLLKKK. (TIF 25 kb)

Additional file 5: Table S2. Results from CD spectrum deconvolution of all 290 samples, with two different algorithms. (PDF 66 kb)

\section{Abbreviations}

CD: Circular dichroism; CMC: Critical micellar concentration; CNS: Central nervous system; DMPC: Dimyristoyl phosphatidylcholine; DMPG: Dimyristoyl phosphatidylglycerol; DPC: n-Dodecyl phosphocholine; EAE: Experimental autoimmune encephalomyelitis; EAN: Experimental autoimmune neuritis; GBS: Guillain-Barré syndrome; MBP: Myelin basic protein; MHC: Major histocompatibility complex; MOBP: Myelin-associated oligodendrocytic basic protein; MOG: Myelin-oligodendrocyte glycoprotein; MS: Multiple sclerosis; OCD: Oriented CD; PLP: Proteolipid protein; PNS: Peripheral nervous system; SDS: Sodium dodecyl sulfate; SRCD: Synchrotron radiation CD; TCR: T cell receptor; TFE: Trifluoroethanol

\section{Acknowledgements \\ We extend our special thanks to the beamline staff at SOLEIL and ISA, as well as to staff at the Biocenter Oulu Proteomics and Protein Analysis Core Facility.}

\section{Funding}

This study has been supported by the Emil Aaltonen Foundation (Finland), the Sigrid Jusélius Foundation (Finland), the Academy of Finland, and the Research Council of Norway (SYNKNØYT program). The funders had no role in the design of the study, the collection, analysis, and interpretation of data, or in writing the manuscript.

Availability of data and materials

All data generated or analysed during this study are included in this published article and its Additional files. Raw data files are available from the corresponding author on reasonable request. 


\section{Authors' contributions}

JT planned and carried out experiments, analysed data, and was a major contributor in writing the manuscript. AR planned and carried out experiments, optimized methodologies, and participated in writing the manuscript. SR analysed data and participated in writing the manuscript. PK obtained funding for the study, planned experiments and analysed data, and was a major contributor in writing the manuscript. All authors read and approved the final manuscript.

\section{Competing interests}

The authors declare that they have no competing interests.

\section{Consent for publication}

Not applicable.

Ethics approval and consent to participate

Not applicaple.

\section{Publisher's Note}

Springer Nature remains neutral with regard to jurisdictional claims in published maps and institutional affiliations.

\section{Received: 4 January 2017 Accepted: 7 March 2017}

Published online: 24 March 2017

\section{References}

1. Compston A, Coles A. Multiple sclerosis. Lancet. 2008;372:1502-17.

2. Dendrou CA, Fugger L, Friese MA. Immunopathology of multiple sclerosis. Nat Rev Immunol. 2015;15:545-58.

3. Valli A, Sette A, Kappos L, Oseroff C, Sidney J, Miescher G, Hochberger M, Albert ED, Adorini L. Binding of myelin basic protein peptides to human histocompatibility leukocyte antigen class II molecules and their recognition by T cells from multiple sclerosis patients. J Clin Invest. 1993;91:616-28.

4. Bielekova B, Sung MH, Kadom N, Simon R, McFarland H, Martin R. Expansion and functional relevance of high-avidity myelin-specific CD4+ T cells in multiple sclerosis. J Immunol. 2004;172:3893-904.

5. Greer JM, Csurhes PA, Cameron KD, McCombe PA, Good MF, Pender MP. Increased immunoreactivity to two overlapping peptides of myelin proteolipid protein in multiple sclerosis. Brain. 1997;120:1447-60.

6. Mendel I, Kerlero de Rosbo N, Ben-Nun A. Delineation of the minimal encephalitogenic epitope within the immunodominant region of myelin oligodendrocyte glycoprotein: diverse $\mathrm{V}$ beta gene usage by $T$ cells recognizing the core epitope encephalitogenic for $T$ cell receptor $V$ beta $b$ and T cell receptor V beta a H-2b mice. Eur J Immunol. 1996;26:2470-9.

7. de Rosbo NK, Kaye JF, Eisenstein M, Mendel I, Hoeftberger R, Lassmann H, Milo R, Ben-Nun A. The myelin-associated oligodendrocytic basic protein region MOBP15-36 encompasses the immunodominant major encephalitogenic epitope(s) for SJL/J mice and predicted epitope(s) for multiple sclerosis-associated HLA-DRB1*1501. J Immunol. 2004;173:1426-35.

8. Holz A, Bielekova B, Martin R, Oldstone MB. Myelin-associated oligodendrocytic basic protein: identification of an encephalitogenic epitope and association with multiple sclerosis. J Immunol. 2000;164:1103-9.

9. Denic $A$, Johnson AJ, Bieber AJ, Warrington $A E$, Rodriguez M, Pirko I. The relevance of animal models in multiple sclerosis research. Pathophysiology. 2011:18:21-9.

10. Csurhes PA, Sullivan AA, Green $K$, Pender MP, McCombe PA. T cell reactivity to P0, P2, PMP-22, and myelin basic protein in patients with Guillain-Barré syndrome and chronic inflammatory demyelinating polyradiculoneuropathy. J Neurol Neurosurg Psychiatry. 2005:76:1431-9.

11. Hughes RA, Cornblath DR. Guillain-Barré syndrome. Lancet. 2005;366:1653-66.

12. Makowska A, Pritchard J, Sanvito L, Gregson N, Peakman M, Hayday A, Hughes R. Immune responses to myelin proteins in Guillain-Barré syndrome. J Neurol Neurosurg Psychiatry. 2008;79:664-71.

13. Loshaj-Shala A, Regazzoni L, Daci A, Orioli M, Brezovska K, Panovska AP, Beretta G, Suturkova L. Guillain Barré syndrome (GBS): new insights in the molecular mimicry between C. jejuni and human peripheral nerve (HPN) proteins. J Neuroimmunol. 2015;289:168-76.

14. Willison HJ, Jacobs BC, van Doorn PA. Guillain-Barré syndrome. Lancet. 2016:388:717-27.

15. Virtanen JO, Jacobson S. Viruses and multiple sclerosis. CNS Neurol Disord Drug Targets. 2012;11:528-44.
16. Virtanen JO, Wohler J, Fenton K, Reich DS, Jacobson S. Oligoclonal bands in multiple sclerosis reactive against two herpesviruses and association with magnetic resonance imaging findings. Mult Scler. 2014;20:27-34.

17. Wuest SC, Mexhitaj I, Chai NR, Romm E, Scheffel J, Xu B, Lane K, Wu T, Bielekova B. A complex role of herpes viruses in the disease process of multiple sclerosis. PLoS One. 2014;9:e105434.

18. Zheng MM, Zhang XH. Cross-reactivity between human cytomegalovirus peptide 981-1003 and myelin oligodendroglia glycoprotein peptide 35-55 in experimental autoimmune encephalomyelitis in Lewis rats. Biochem Biophys Res Commun. 2014;443:1118-23.

19. Wucherpfennig KW, Strominger JL. Molecular mimicry in T cell-mediated autoimmunity: viral peptides activate human $\mathrm{T}$ cell clones specific for myelin basic protein. Cell. 1995;80:695-705.

20. Anthony JS, Moscarello MA. A conformation change induced in the basic encephalitogen by lipids. Biochim Biophys Acta. 1971:243:429-33.

21. Chao LP, Einstein ER. Physical properties of the bovine encephalitogenic protein; molecular weight and conformation. J Neurochem. 1970;17:1121-32.

22. Epand RM, Moscarello MA, Zierenberg B, Vail WJ. The folded conformation of the encephalitogenic protein of the human brain. Biochemistry. 1974;13:1264-7.

23. Haas H, Oliveira CL, Torriani IL, Polverini E, Fasano A, Carlone G, Cavatorta P, Riccio P. Small angle x-ray scattering from lipid-bound myelin basic protein in solution. Biophys J. 2004;86:455-60.

24. Krigbaum WR, Hsu TS. Molecular conformation of bovine A1 basic protein, a coiling macromolecule in aqueous solution. Biochemistry. 1975;14:2542-6.

25. Mendz GL, Moore WJ, Brown LR, Martenson RE. Interaction of myelin basic protein with micelles of dodecylphosphocholine. Biochemistry. 1984;23:6041-6.

26. Polverini E, Fasano A, Zito F, Riccio P, Cavatorta P. Conformation of bovine myelin basic protein purified with bound lipids. Eur Biophys J. 1999;28:351-5.

27. Wood DD, Moscarello MA, Epand RM. Studies on chemically modified forms of the myelin basic protein: requirements for encephalitogenicity. FEBS Lett. 1976;66:290-2.

28. Vassall KA, Bessonov K, De Avila M, Polverini E, Harauz G. The effects of threonine phosphorylation on the stability and dynamics of the central molecular switch region of $18.5-\mathrm{kDa}$ myelin basic protein. PLoS One. 2013;8:e68175.

29. Vassall KA, Jenkins AD, Bamm W, Harauz G. Thermodynamic analysis of the disorder-to-alpha-helical transition of 18.5-kDa myelin basic protein reveals an equilibrium intermediate representing the most compact conformation. J Mol Biol. 2015;427:1977-92.

30. Wang C, Neugebauer U, Bürck J, Myllykoski M, Baumgärtel P, Popp J, Kursula P. Charge isomers of myelin basic protein: structure and interactions with membranes, nucleotide analogues, and calmodulin. PLoS One. 2011;6:e19915.

31. Muruganandam G, Bürck J, Ulrich AS, Kursula I, Kursula P. Lipid membrane association of myelin proteins and peptide segments studied by oriented and synchrotron radiation circular dichroism spectroscopy. J Phys Chem B. 2013;117:14983-93.

32. Musse AA, Boggs JM, Harauz G. Deimination of membrane-bound myelin basic protein in multiple sclerosis exposes an immunodominant epitope. Proc Natl Acad Sci U S A. 2006;103:4422-7.

33. Aggarwal $S$, Snaidero $N$, Pähler $G$, Frey $S$, Sánchez $P$, Zweckstetter $M$, Janshoff A, Schneider A, Weil MT, Schaap IA, Görlich D, Simons M. Myelin membrane assembly is driven by a phase transition of myelin basic proteins into a cohesive protein meshwork. PLoS Biol. 2013;11:e1001577.

34. von Budingen HC, Hauser SL, Ouallet JC, Tanuma N, Menge T, Genain CP. Frontline: Epitope recognition on the myelin/oligodendrocyte glycoprotein differentially influences disease phenotype and antibody effector functions in autoimmune demyelination. Eur J Immunol. 2004:34:2072-83.

35. Lees JG, Smith BR, Wien F, Miles AJ, Wallace BA. CDtool-an integrated software package for circular dichroism spectroscopic data processing, analysis, and archiving. Anal Biochem. 2004;332:285-9.

36. Shen Y, Maupetit J, Derreumaux P, Tuffery P. Improved PEP-FOLD Approach for Peptide and Miniprotein Structure Prediction. J Chem Theory Comput. 2014;10:4745-58.

37. Thevenet P, Shen Y, Maupetit J, Guyon F, Derreumaux P, Tuffery P. PEPFOLD: an updated de novo structure prediction server for both linear and disulfide bonded cyclic peptides. Nucleic Acids Res. 2012:40:W288-93.

38. Lomize MA, Pogozheva ID, Joo H, Mosberg HI, Lomize AL. OPM database and PPM web server: resources for positioning of proteins in membranes. Nucleic Acids Res. 2012;40:D370-6. 
39. Whitmore L, Wallace BA. DICHROWEB, an online server for protein secondary structure analyses from circular dichroism spectroscopic data. Nucleic Acids Res. 2004;32:W668-73.

40. Micsonai A, Wien F, Kernya L, Lee YH, Goto Y, Refregiers M, Kardos J. Accurate secondary structure prediction and fold recognition for circular dichroism spectroscopy. Proc Natl Acad Sci U S A. 2015;112:E3095-103.

41. Ruskamo S, Yadav RP, Sharma S, Lehtimäki M, Laulumaa S, Aggarwal S, Simons M, Bürck J, Ulrich AS, Juffer AH, Kursula I, Kursula P. Atomic resolution view into the structure-function relationships of the human myelin peripheral membrane protein P2. Acta Crystallogr D Biol Crystallogr. 2014:70:165-76.

42. Jo E, Boggs JM. Aggregation of acidic lipid vesicles by myelin basic protein: dependence on potassium concentration. Biochemistry. 1995;34:13705-16.

43. Kursula P. Structural properties of proteins specific to the myelin sheath. Amino Acids. 2008:34:175-85.

44. Majava V, Polverini E, Mazzini A, Nanekar R, Knoll W, Peters J, Natali F, Baumgärtel P, Kursula I, Kursula P. Structural and functional characterization of human peripheral nervous system myelin protein P2. PLoS One. 2010;5:e10300.

45. Ahmed MA, Bamm W, Harauz G, Ladizhansky V. Solid-state NMR spectroscopy of membrane-associated myelin basic protein - conformation and dynamics of an immunodominant epitope. Biophys J. 2010;99:1247-55.

46. Ahmed MA, De Avila M, Polverini E, Bessonov K, Bamm W, Harauz G. Solution nuclear magnetic resonance structure and molecular dynamics simulations of a murine $18.5 \mathrm{kDa}$ myelin basic protein segment (S72-S107) in association with dodecylphosphocholine micelles. Biochemistry. 2012;51:7475-87.

47. Farès $C$, Libich DS, Harauz G. Solution NMR structure of an immunodominant epitope of myelin basic protein. Conformational dependence on environment of an intrinsically unstructured protein. FEBS J. 2006;273:601-14.

48. Libich DS, Harauz G. Solution NMR and CD spectroscopy of an intrinsically disordered, peripheral membrane protein: evaluation of aqueous and membrane-mimetic solvent conditions for studying the conformational adaptability of the $18.5 \mathrm{kDa}$ isoform of myelin basic protein (MBP). Eur Biophys J. 2008;37:1015-29.

49. Libich DS, Ahmed MA, Zhong L, Bamm W, Ladizhansky V, Harauz G. Fuzzy complexes of myelin basic protein: NMR spectroscopic investigations of a polymorphic organizational linker of the central nervous system. Biochem Cell Biol. 2010;88:143-55.

50. Myllykoski M, Baumgärtel P, Kursula P. Conformations of peptides derived from myelin-specific proteins in membrane-mimetic conditions probed by synchrotron radiation CD spectroscopy. Amino Acids. 2012;42:1467-74.

51. Li Y, Li H, Martin R, Mariuzza RA. Structural basis for the binding of an immunodominant peptide from myelin basic protein in different registers by two HLA-DR2 proteins. J Mol Biol. 2000;304:177-88.

52. Katsara M, Yuriev E, Ramsland PA, Deraos G, Tselios T, Matsoukas J, Apostolopoulos V. A double mutation of MBP(83-99) peptide induces IL-4 responses and antagonizes IFN-gamma responses. J Neuroimmunol. 2008:200:77-89.

53. Potamitis C, Matsoukas MT, Tselios T, Mavromoustakos T, Golič GS Conformational analysis of the MBP83-99 (Phe91) and MBP83-99 (Tyr91) peptide analogues and study of their interactions with the HLA-DR2 and human TCR receptors by using molecular dynamics. J Comput Aided Mol Des. 2011;25:837-53.

54. Lu X, Qi J, Shi Y, Wang M, Smith DF, Heimburg-Molinaro J, Zhang Y, Paulson JC, Xiao H, Gao GF. Structure and receptor binding specificity of hemagglutinin $\mathrm{H} 13$ from avian influenza A virus H13N6. J Virol. 2013:87:9077-85.

55. Mendel I, Kerlero de Rosbo N, Ben-Nun A. A myelin oligodendrocyte glycoprotein peptide induces typical chronic experimental autoimmune encephalomyelitis in $\mathrm{H}-2 \mathrm{~b}$ mice: fine specificity and $\mathrm{T}$ cell receptor $\mathrm{V}$ beta expression of encephalitogenic T cells. Eur J Immunol. 1995;25:1951-9.

56. Moreno M, Guo F, Mills Ko E, Bannerman P, Soulika A, Pleasure D. Origins and significance of astrogliosis in the multiple sclerosis model, MOG peptide EAE. J Neurol Sci. 2013:333:55-9.

57. Rich C, Link JM, Zamora A, Jacobsen H, Meza-Romero R, Offner H, Jones R, Burrows GG, Fugger L, Vandenbark AA. Myelin oligodendrocyte glycoprotein-35-55 peptide induces severe chronic experimental autoimmune encephalomyelitis in HLA-DR2-transgenic mice. Eur J Immunol. 2004;34:1251-61.

58. Clements CS, Reid HH, Beddoe T, Tynan FE, Perugini MA, Johns TG, Bernard CC, Rossjohn J. The crystal structure of myelin oligodendrocyte glycoprotein, a key autoantigen in multiple sclerosis. Proc Natl Acad Sci U S A. 2003;100:11059-64.

59. Tselios T, Aggelidakis M, Tapeinou A, Tseveleki V, Kanistras I, Gatos D, Matsoukas J. Rational design and synthesis of altered peptide ligands based on human myelin oligodendrocyte glycoprotein 35-55 epitope: inhibition of chronic experimental autoimmune encephalomyelitis in mice. Molecules. 2014;19:17968-84.

60. Recks MS, Grether NB, van der Broeck F, Ganscher A, Wagner N, Henke E, Ergun S, Schroeter M, Kuerten S. Four different synthetic peptides of proteolipid protein induce a distinct antibody response in MP4-induced experimental autoimmune encephalomyelitis. Clin Immunol. 2015;159:93-106.

61. Kennedy MK, Tan LJ, Dal Canto MC, Tuohy VK, Lu ZJ, Trotter JL, Miller SD. Inhibition of murine relapsing experimental autoimmune encephalomyelitis by immune tolerance to proteolipid protein and its encephalitogenic peptides. J Immunol. 1990;144:909-15.

62. Appadu A, Jelokhani-Niaraki M, DeBruin L. Conformational Changes and Association of Membrane-Interacting Peptides in Myelin Membrane Models: A Case of the C-Terminal Peptide of Proteolipid Protein and the Antimicrobial Peptide Melittin. J Phys Chem B. 2015;119:14821-30.

63. Stecca B, Southwood CM, Gragerov A, Kelley KA, Friedrich VLJ, Gow A. The evolution of lipophilin genes from invertebrates to tetrapods: DM-20 cannot replace proteolipid protein in CNS myelin. J Neurosci. 2000;20:4002-10.

64. Greer JM, Denis B, Sobel RA, Trifilieff E. Thiopalmitoylation of myelin proteolipid protein epitopes enhances immunogenicity and encephalitogenicity. J Immunol. 2001;166:6907-13.

65. Pfender NA, Grosch S, Roussel G, Koch M, Trifilieff E, Greer JM. Route of uptake of palmitoylated encephalitogenic peptides of myelin proteolipid protein by antigen-presenting cells: importance of the type of bond between lipid chain and peptide and relevance to autoimmunity. J Immunol. 2008;180:1398-404.

66. Inouye $H$, Kirschner DA. Evolution of myelin ultrastructure and the major structural myelin proteins. Brain Res. 2016;1641:43-63.

67. Daffu G, Sohi J, Kamholz J. Proteolipid protein dimerization at cysteine 108: Implications for protein structure. Neurosci Res. 2012;74:144-55.

68. Dhaunchak AS, Colman DR, Nave KA. Misalignment of PLP/DM20 transmembrane domains determines protein misfolding in PelizaeusMerzbacher disease. J Neurosci. 2011;31:14961-71.

69. Massilamany C, Steffen D, Reddy J. An epitope from Acanthamoeba castellanii that cross-react with proteolipid protein 139-151-reactive T cells induces autoimmune encephalomyelitis in SJL mice. J Neuroimmunol. 2010:219:17-24.

70. Olson JK, Croxford JL, Calenoff MA, Dal Canto MC, Miller SD. A virus-induced molecular mimicry model of multiple sclerosis. J Clin Invest. 2001;108:311-8.

71. Dhaunchak AS, Nave KA. A common mechanism of PLP/DM20 misfolding causes cysteine-mediated endoplasmic reticulum retention in oligodendrocytes and Pelizaeus-Merzbacher disease. Proc Natl Acad Sci U S A. 2007:104:17813-8.

72. Trapp BD, Mclntyre LJ, Quarles RH, Sternberger NH, Webster HD. Immunocytochemical localization of rat peripheral nervous system myelin proteins: P2 protein is not a component of all peripheral nervous system myelin sheaths. Proc Natl Acad Sci U S A. 1979;76:3552-6.

73. Zenker J, Stettner M, Ruskamo S, Domènech-Estévez E, Baloui H, Médard JJ, Verheijen MH, Brouwers JF, Kursula P, Kieseier BC, Chrast R. A role of peripheral myelin protein 2 in lipid homeostasis of myelinating Schwann cells. Glia. 2014;62:1502-12.

74. Abramsky O, Teitelbaum D, Webb C, Arnon R. Neuritogenic and encephalitogenic properties of the peripheral nerve basic proteins. J Neuropathol Exp Neurol. 1975;34:36-45.

75. Uyemura K, Suzuki M, Kitamura K, Horie K, Ogawa Y, Matsuyama H, Nozaki S, Muramatsu I. Neuritogenic determinant of bovine $\mathrm{P} 2$ protein in peripheral nerve myelin. J Neurochem. 1982;39:895-8.

76. Sedzik J, Blaurock AE, Hoechli M. Reconstituted P2/myelin-lipid multilayers. J Neurochem. 1985;45:844-52.

77. Suresh S, Wang C, Nanekar R, Kursula P, Edwardson JM. Myelin basic protein and myelin protein 2 act synergistically to cause stacking of lipid bilayers. Biochemistry. 2010;49:3456-63.

78. Taylor WA, Brostoff SW, Hughes RA. P2 specific lymphocyte transformation in Guillain-Barré syndrome and chronic idiopathic demyelinating polyradiculoneuropathy. J Neurol Sci. 1991;104:52-5.

79. Laulumaa S, Nieminen T, Lehtimäki M, Aggarwal S, Simons M, Koza MM Vattulainen I, Kursula P, Natali F. Dynamics of the peripheral membrane 
protein P2 from human myelin measured by neutron scattering-a comparison between wild-type protein and a hinge mutant. PLoS One. 2015;10:e0128954

80. Constantinescu CS, Farooqi N, O'Brien K, Gran B. Experimental autoimmune encephalomyelitis (EAE) as a model for multiple sclerosis (MS). Br J Pharmacol. 2011;164:1079-106.

81. Pettinelli CB, McFarlin DE. Adoptive transfer of experimental allergic encephalomyelitis in SJL/J mice after in vitro activation of lymph node cells by myelin basic protein: requirement for Lyt 1+ 2- T lymphocytes. J Immunol. 1981;127:1420-3.

82. Reboldi A, Coisne C, Baumjohann D, Benvenuto F, Bottinelli D, Lira S, Uccelli A, Lanzavecchia A, Engelhardt B, Sallusto F. C-C chemokine receptor 6-regulated entry of $\mathrm{TH}-17$ cells into the CNS through the choroid plexus is required for the initiation of EAE. Nat Immunol. 2009;10:514-23.

83. Sospedra M, Zhao Y, zur Hausen H, Muraro PA, Hamashin C, de Villiers EM, Pinilla C, Martin R. Recognition of conserved amino acid motifs of common viruses and its role in autoimmunity. PLoS Pathog. 2005;1:e41.

84. Sethi DK, Schubert DA, Anders AK, Heroux A, Bonsor DA, Thomas CP, Sundberg EJ, Pyrdol J, Wucherpfennig KW. A highly tilted binding mode by a self-reactive T cell receptor results in altered engagement of peptide and MHC. J Exp Med. 2011;208:91-102.

85. Yin Y, Li Y, Mariuzza RA. Structural basis for self-recognition by autoimmune T-cell receptors. Immunol Rev. 2012;250:32-48.

86. Belogurov A, Kuzina E, Kudriaeva A, Kononikhin A, Kovalchuk S, Surina Y, Smirnov I, Lomakin Y, Bacheva A, Stepanov A, Karpova Y, Lyupina Y, Kharybin O, Melamed D, Ponomarenko N, Sharova N, Nikolaev E, Gabibov A. Ubiquitin-independent proteosomal degradation of myelin basic protein contributes to development of neurodegenerative autoimmunity. FASEB J. 2015;29:1901-13.

87. Vassall KA, Bamm W, Harauz G. MyelStones: the executive roles of myelin basic protein in myelin assembly and destabilization in multiple sclerosis. Biochem J. 2015:472:17-32.

88. Bates IR, Feix JB, Boggs JM, Harauz G. An immunodominant epitope of myelin basic protein is an amphipathic alpha-helix. J Biol Chem. 2004;279:5757-64.

89. Shaharabani R, Ram-On M, Avinery R, Aharoni R, Arnon R, Talmon Y, Beck R. Structural Transition in Myelin Membrane as Initiator of Multiple Sclerosis. J Am Chem Soc. 2016;138:12159-65.

90. Harkiolaki M, Holmes SL, Svendsen P, Gregersen JW, Jensen LT, McMahon R, Friese MA, van Boxel G, Etzensperger R, Tzartos JS, Kranc K, Sainsbury S, Harlos K, Mellins ED, Palace J, Esiri MM, van der Merwe PA, Jones EY, Fugger L. T cell-mediated autoimmune disease due to low-affinity crossreactivity to common microbial peptides. Immunity. 2009;30:348-57.

91. Fernández-Menéndez S, Fernández-Morán M, Fernández-Vega I, PérezÁlvarez A, Villafani-Echazú J. Epstein-Barr virus and multiple sclerosis. From evidence to therapeutic strategies. J Neurol Sci. 2016;361:213-9.

92. Chowell D, Krishna S, Becker PD, Cocita C, Shu J, Tan X, Greenberg PD, Klavinskis LS, Blattman JN, Anderson KS. TCR contact residue hydrophobicity is a hallmark of immunogenic CD8+ T cell epitopes. Proc Natl Acad Sci U S A. 2015;112:E1754-62.

93. Huang L, Kuhls MC, Eisenlohr LC. Hydrophobicity as a driver of MHC class antigen processing. EMBO J. 2011;30:1634-44.

94. Apostolopoulos V, Deraos G, Matsoukas MT, Day S, Stojanovska L, Tselios T, Androutsou ME, Matsoukas J. Cyclic citrullinated MBP87-99 peptide stimulates T cell responses: Implications in triggering disease. Bioorg Med Chem. 2017;25:528-38.

95. Day S, Tselios T, Androutsou ME, Tapeinou A, Frilligou I, Stojanovska L, Matsoukas J, Apostolopoulos V. Mannosylated Linear and Cyclic Single Amino Acid Mutant Peptides Using a Small 10 Amino Acid Linker Constitute Promising Candidates Against Multiple Sclerosis. Front Immunol. 2015;6:136.

96. Deraos G, Rodi M, Kalbacher H, Chatzantoni K, Karagiannis F, Synodinos L, Plotas P, Papalois A, Dimisianos N, Papathanasopoulos P, Gatos D, Tselios T, Apostolopoulos V, Mouzaki A, Matsoukas J. Properties of myelin altered peptide ligand cyclo(87-99)(Ala91, Ala96)MBP87-99 render it a promising drug lead for immunotherapy of multiple sclerosis. Eur J Med Chem. 2015;101:13-23.

97. Grigoriadis N, Tselios T, Deraos S, Orologas A, Deraos G, Matsoukas J, Mavromatis I, Milonas I. Animal models of central nervous system immunemediated diseases: therapeutic interventions with bioactive peptides and mimetics. Curr Med Chem. 2005;12:1513-9.
98. Katsara M, Deraos G, Tselios T, Matsoukas J, Apostolopoulos V. Design of novel cyclic altered peptide ligands of myelin basic protein MBP83-99 that modulate immune responses in SJL/J mice. J Med Chem. 2008;51:3971-8.

99. Dagliyan O, Proctor EA, D'Auria KM, Ding F, Dokholyan NV. Structural and dynamic determinants of protein-peptide recognition. Structure. 2011;19:1837-45.

100. Lunemann JD, Ruckert S, Kern F, Wendling $U$, van der Zee R, Volk HD, Zipp F. Cross-sectional and longitudinal analysis of myelin-reactive T cells in patients with multiple sclerosis. J Neurol. 2004;251:1111-20.

101. Carotenuto A, D'Ursi AM, Nardi E, Papini AM, Rovero P. Conformational analysis of a glycosylated human myelin oligodendrocyte glycoprotein peptide epitope able to detect antibody response in multiple sclerosis. J Med Chem. 2001:44:2378-81.

\section{Submit your next manuscript to BioMed Central and we will help you at every step:}

- We accept pre-submission inquiries

- Our selector tool helps you to find the most relevant journal

- We provide round the clock customer support

- Convenient online submission

- Thorough peer review

- Inclusion in PubMed and all major indexing services

- Maximum visibility for your research

Submit your manuscript at www.biomedcentral.com/submit
) Biomed Central 